\title{
Laparoskopik kolesistektomi uygulanan olgularda safra kesesinin histopatolojik profili
}

\author{
Histopathological profile of the gallbladder in cases who have undergone laparoscopic \\ cholecystectomy
}

Ahliman AMIRASLANOV, Kenan YUSIFF-ZADE, Jamal MUSAYEV

\section{ÖZET}

Amaç: Laparoskopik kolesistektomi uygulanan olgularda safra kesesi hastalıklarının dağılımını belirlemek amaçlanmıştır.

Hastalar ve Yöntem: Laparoskopik kolesistektomi uygulanan toplam 404 olguya ait kolesistektomi spesimeninin patolojik özellikleri tekrar gözden geçirildi. Olgulara ait lamlar ve patoloji raporları yeniden değerlendirildi.

Bulgular: Üçyüz iki olgu $(\% 74,75)$ kadın, 102 olgu $(\% 25,25)$ ise erkekti. Olguların yaş aralığ $16-80$, yaş ortalaması $47,68 \pm 12,93$ idi. En çok rastlanan hastalıklar 393 olguda görülen kolelitiazis ve 363 olguda görülen kronik kolesistitti. Ksantogranulomatöz kolesistitli tek olgumuzda safra kesesi intraoperatif olarak malignite açısından kuşkulu bulunmuştur. Kırk altı olguda metaplazi, dört olguda displazi ve sadece bir olguda insidental olarak adenokarsinom belirlendi.

Sonuç: Laparoskopik kolesistektomi uygulanan olgularda safra kesesinde malign tumor insidansı çok düşüktü $(\% 0,24)$. Klinik olarak bulgu göstermeyen malignitelerin saptanabilmesi veya ksantogranulomatöz kolesistit gibi malignite kuşkusu oluşturan bulguların ekarte edilmesi için kolesistektomi spesimenlerinin rutin olarak, yeterli sayıda örneklerin histopatolojik incelemeye alınması gerektiği görüşündeyiz.

Anahtar kelimeler: Laparoskopik kolesistektomi, Safra kesesi, Histopatoloji

Ahliman Amiraslanov

Onkoloji Anabilim Dall, Azerbaycan Tip Üniversitesi, Bakü, Azerbaycan

Kenan Yusif-zade

Genel Cerrahi Kliniği, Devlet Sinır Hizmetinin Askeri Hastanesi, Bakü, Azerbaycan

Jamal Musayev (®)

Patoloji Anabilim Dall, Azerbaycan Tıp Üniversitesi, Bakü, Azerbaycan

e-mail:camal@box.az

Gönderilme/ Submitted: 21.10.2014

Kabul/ Accepted: 09.12.2014

\begin{abstract}
Objectives: We define the profile of gallbladder diseases in recipients of a laparoscopic cholecystectomy.

Patients and Methods: Pathological features of cholecystectomy specimens of 404 patients were reviewed. Microslides and pathology reports of the patients were reevaluated.

Results: Three hundred and two $(74.75 \%)$ of patients were female, $102(25.25 \%)$ were male. The age range of patients was $16-$ 80 and mean age was $47.68 \pm 12.93$. Most common diseases were cholelithiasis in 393 cases and chronic cholecystitis in 363 cases. The gallbladder of one of the patients with xanthogranulomatous cholecystitis has been suggestive of malignancy. Metaplasia in 46 patients, dysplasia in 4 patients and adenocarcinoma in just one patient were detected.

Conclusion: The incidence of malignant tumors in the gallbladder of recipients of a laparoscopic cholecystectomy is very low $(0.24 \%)$. We suggest that, cholecystectomy specimens must be routinely examined histopathologically with an adequate number of samples for detection of malignancies without clinical signs and for the exclusion of findings of likely malignancies such as xanthogranulomatous cholecystitis.
\end{abstract}

Keywords: Laparoscopic cholecystectomy, Gallbladder, Histopathology

\section{Giriş}

Kolesistektomi spesimenleri bir patoloji laboratuvarında rutin olarak incelemeye alınan, sıkca karşılaşılan bir spesimen türüdür. Genellikle, safra kesesinden ibaret olan bu spesimenler bazen küçük karaciğer dokusu veya lenf nodu da içermektedir. Safra kesesi hastalıkları çoğunlukla benign, non-neoplastik hastalıklardır. Nadiren safra kesesinde malign tümörlere rastlanmaktadır ve bunların da büyük kısmını adenokarsinomlar oluşturmaktadır. Safra kesesinde malign tümörlerin önemli bir kısmı semptomsuzdur ve postoperatif histopatolojik incelemede insidental olarak saptanmaktadır [1]. $\mathrm{Bu}$ açıdan kolesistektomi materyallerinin rutin histopatolojik 
Tablo I. Laparoskopik kolesistektomi uygulanan olguların yaş dağılmı

\begin{tabular}{llll}
\hline Yaş aralı̆̆ & $\begin{array}{l}\text { Kadın } \\
\text { n (\%) }\end{array}$ & $\begin{array}{l}\text { Erkek } \\
\mathbf{n}(\%)\end{array}$ & $\begin{array}{l}\text { Toplam } \\
\mathbf{n}(\%)\end{array}$ \\
\hline $16-20$ & $4(1,33 \%)$ & $1(0,98 \%)$ & $5(1,24 \%)$ \\
$21-30$ & $28(9,27 \%)$ & $7(6,87 \%)$ & $35(8,67 \%)$ \\
$31-40$ & $57(18,87 \%)$ & $16(15,68 \%)$ & $73(18,07 \%)$ \\
$41-50$ & $78(25,83 \%)$ & $33(32,35 \%)$ & $111(27,47 \%)$ \\
$51-60$ & $85(28,15 \%)$ & $33(32,35 \%)$ & $118(29,21 \%)$ \\
$61-70$ & $39(12,91 \%)$ & $7(6,87 \%)$ & $46(11,38 \%)$ \\
$71-80$ & $11(3,64 \%)$ & $5(4,9 \%)$ & $16(3,96 \%)$ \\
Toplam & $302(100 \%)$ & $102(100 \%)$ & $404(100 \%)$ \\
\hline
\end{tabular}

incelemesi önem taşımaktadır. Çalışmamızda laparoskopik kolesistektomi uygulanan olgulara ait safra kesesinin histopatolojik profilini belirlemek amaçlanmıştır.

\section{Hastalar ve Yöntem}

Çalışmaya toplam 404 laparoskopik kolesistektomi spesimeni dahil edilmiştir. Olgulara ait histopatolojik inceleme raporları ve lamlar tekrar değerlendirilmiştir. Histopatolojik inceleme için her spesimenden en az 3, en çok 7 örnek alınmıştır ve hazırlanan kesitler hematoksilen-eosin ile boyanmıştır. Bütün olgularda safra kesesi lümeninde taş varlığı, taşların tipi, kese duvarında inflamasyon türü, kolesterolozis, polip, metaplazi, displazi, tümör ve diğer lezyonların varlığına dikkat edilmiştir. Belirtilen özellikler olgulara ait demografik bilgiler ile birlikte geriye dönük olarak analiz edilmiştir.

\section{Bulgular}

Üçyüz iki olgu $(\% 74,75)$ kadın, 102 olgu $(\% 25,25)$ ise erkekti. Olguların yas aralığ 1 16-80'di ve yas ortalaması 47,68 $\pm 12,93$ olarak belirlendi. Kadın ve erkeklerin yaş ortalamasında önemli fark bulunmadı (Tablo I). Otuz bir spesimende $(\% 7,67)$ safra kesesinde akut kolesistit, 363 spesimende $(\% 89,85)$ kronik kolesistit, dokuz spesimende $(\% 2,23)$ polip, sadece bir spesimende $(\% 0,25)$ ise malign tümör görüldü. Olgularımızda belirlenen safra kesesi

Tablo II. Laparoskopik kolesistektomi uygulanan olgularda patolojik bulguların dağılımı

\begin{tabular}{|c|c|c|c|c|c|c|}
\hline \multirow{2}{*}{$\begin{array}{l}\text { Bulgular } \\
\text { Kolelitiazis }\end{array}$} & \multicolumn{2}{|c|}{$\begin{array}{c}\text { Kadın } \\
n=302(74,75 \%)\end{array}$} & \multicolumn{2}{|c|}{$\begin{array}{c}\text { Erkek } \\
\mathrm{n}=102(25,25 \%) \\
\end{array}$} & \multicolumn{2}{|c|}{$\begin{array}{c}\text { Toplam } \\
\mathrm{n}=\mathbf{4 0 4}(\mathbf{1 0 0 \% )})\end{array}$} \\
\hline & 298 & $(98,68 \%)$ & 95 & $(93,13 \%)$ & 393 & $(97,27 \%)$ \\
\hline Miks kolesterol taş1 & 162 & $(53,64 \%)$ & 59 & $(57,84 \%)$ & 221 & $(54,7 \%)$ \\
\hline Saf kolesterol taş1 & 84 & $(27,81 \%)$ & 12 & $(11,76 \%)$ & 96 & $(23,76 \%)$ \\
\hline Siyah pigment taş1 & 33 & $(10,92 \%)$ & 15 & $(14,7 \%)$ & 48 & $(11,88 \%)$ \\
\hline Kahve pigment taşı & 19 & $(6,29 \%)$ & 9 & $(8,82 \%)$ & 28 & $(6,93 \%)$ \\
\hline İnflamasyon & 294 & $(97,35 \%)$ & 100 & $(98,03 \%)$ & 394 & $(97,52 \%)$ \\
\hline Akut & 21 & $(6,95 \%)$ & 10 & $(9,8 \%)$ & 31 & $(7,67 \%)$ \\
\hline Flegmonöz & 17 & $(5,62 \%)$ & 6 & $(5,88 \%)$ & 23 & $(5,69 \%)$ \\
\hline Gangrenöz & 4 & $(1,32 \%)$ & 4 & $(3,92 \%)$ & 8 & $(1,98 \%)$ \\
\hline Kronik & 273 & $(90,39 \%)$ & 90 & $(88,23 \%)$ & 363 & $(89,85 \%)$ \\
\hline Spesifik olmayan & 265 & $(87,74 \%)$ & 87 & $(85,29 \%)$ & 352 & $(87,12 \%)$ \\
\hline Folliküler & 5 & $(1,65 \%)$ & 1 & $(0,98 \%)$ & 6 & $(1,48 \%)$ \\
\hline Eozinofilik & 1 & $(0,33 \%)$ & 1 & $(0,98 \%)$ & 2 & $(0,49 \%)$ \\
\hline Granulomatöz & 2 & $(0,66 \%)$ & 0 & & 2 & $(0,49 \%)$ \\
\hline Ksantogranulomatöz & 0 & & 1 & $(0,98 \%)$ & 1 & $(0,24 \%)$ \\
\hline Kolesterolozis & 35 & $(11,58 \%)$ & 4 & $(3,92 \%)$ & 39 & $(9,65 \%)$ \\
\hline Kolesterol polipi & 3 & $(0,99 \%)$ & 6 & $(5,88 \%)$ & 9 & $(2,22 \%)$ \\
\hline Metaplazi & 37 & $(12,25 \%)$ & 9 & $(8,82 \%)$ & 46 & $(11,38 \%)$ \\
\hline Antral & 31 & $(10,26 \%)$ & 8 & $(7,84 \%)$ & 39 & $(9,65 \%)$ \\
\hline İntestinal & 4 & $(1,32 \%)$ & 0 & & 4 & $(0,99 \%)$ \\
\hline Endokrin & 1 & $(0,33 \%)$ & 1 & $(0,98 \%)$ & 2 & $(0,49 \%)$ \\
\hline Skuamöz & 1 & $(0,33 \%)$ & 0 & & 1 & $(0,24 \%)$ \\
\hline Displazi & 3 & $(0,99 \%)$ & 1 & $(0,98 \%)$ & 4 & $(0,99 \%)$ \\
\hline Düşük dereceli & 2 & $(0,66 \%)$ & 1 & $(0,98 \%)$ & 3 & $(0,74 \%)$ \\
\hline Yüksek dereceli & 1 & $(0,33 \%)$ & 0 & & 1 & $(0,24 \%)$ \\
\hline Karsinom & 1 & $(0,33 \%)$ & $\mathbf{0}$ & & 1 & $(0,24 \%)$ \\
\hline
\end{tabular}


hastalıklarının dağılımı Tablo II'de ayrıntılı olarak gösterilmiştir.

Toplam 393 olguda $(\% 97,03)$ kolelitiazis belirlendi. Miks kolesterol taș 221 olguda $(\% 56,23)$, saf kolesterol tașı 96 olguda $(\% 24,43)$, siyah pigment taşı 48 olguda $(\% 12,21)$, kahve pigment taşı ise 28 olguda $(\% 7,13)$ görüldü.

Olguların sadece 20 'de $(\% 5,08)$ koledokolitiazis saptandı. $\mathrm{Bu}$ olguların preoperatif tanı sürecinde ultrasonografi veya gerektiğinde manyetik rezonans kolanjiyopankreatografi uygulanmış; koledok ve ekstrahepatik safra yollarında obstrüksiyon görülen, aynı zamanda total ve direkt serum bilirubin düzeyi yüksek bulunan olgularda diagnostik endoskopik retrograd kolanjiyopankreatografi ile koledokolitiazis tanısı doğrulanmıştır. Koledokolitiazis belirlenen olgulara ekstrahepatik safra yolu tıkanması preoperatif olarak giderildikten sonra rutin laparoskopik kolesistektomi uygulanmıştır.

Akut kolesistitli olguların yaş ortalaması $49,93 \pm 12,85$ (yaş aralığı 21-73); cinsiyet dağılımında kadın oranı $\% 67,75$ idi. Sekiz olguda $(\% 25,8)$ gangrenöz, 23 olguda ise $(\% 74,2)$ flegmanöz kolesistit izlendi. Kronik kolesistitli olguların yaş ortalaması 47,64 $\pm 12,89$ (yaş aralığı 16-80); kadın olguların oranı \%75,48 idi. Bunlardan altı olguda folliküler kolesistit, iki olguda eozinofilik kolesistit, iki olguda granülömatöz kolesistit, bir olguda ise ksantogranülömatöz kolesistit olarak toplam 11 olguda $(\% 3,03)$ spesifik iltihab bulguları saptand. Ksantogranülömatöz kolesistit belirlenen olgu preoperatif ultrasonografide kese duvarının irregüler kalınlaşması nedeni ile malignite açısından kuşkulu bulunmuştur.

Kolesterolozis 39 olguda $(\% 9,65)$ belirlendi ve bu olguların hepsinde kronik kolesistit mevcuttu. Kolesterolozis bulunan olguların yaş ortalaması 55,61 $\pm 8,33$ (yaş aralığ 132 $75)$, cinsiyet dağılımında kadın oranı \%89,74 ( $\mathrm{n}=35)$ idi.

Safra kesesi polibi bulunan 9 olgunun tamamında kolesterol tip polip görüldü. Her olguda polip sayısı 3-8 adetti ve poliplerin en büyük çapı 1-5 mm arasında değişiyordu. Polip bulunan olguların yaş ortalaması $45,55 \pm 13,9$ (yaş aralığı 18-60) idi. Kolesterolozis belirlenen olgulardan farklı olarak kolesterol polibi daha çok erkelerde ( $\mathrm{n}=6$; \%66,7) görüldü.

Yüzey epitelinde üç olguda düşük dereceli ve bir olguda yüksek dereceli olarak toplam dört olguda $(\% 0,99)$ displazi saptandı (Şekil 1). Displazi belirlenen olguların tamamı kadındı. Yaş aralı̆̆ $166-67$, yaş ortalaması ise $55,0 \pm 8,83$ idi. Ayrıca kronik kolesistit saptanan olguların otuz dokuzunda $(\% 9,63)$ antral, dördünde $(\% 0,98)$ intestinal (Şekil 2), ikisinde $(\% 0,49)$ endokrin, birinde $(\% 0,24)$ ise skuamöz metaplazi olarak toplam 46 olguda $(\% 11,35)$ metaplastik bulgular belirlendi.

Malign tümör görülen tek olgumuz $(\% 0,24) 46$ yaşında kadındı. Preoperatif ve intraoperatif dönemde hastada tümör varlığına dair herhangi bir kuşkulu belirti görülmemiștir. Tümör postoperatif histopatolojik değerlendirme zamanı insidental olarak belirlendi. Makroskopik olarak tümörün en büyük çap $1,7 \mathrm{~cm}$, lokalizasyonu safra kesesi korpusuydu. Olgu kas invazyonu gösteren (pT1b) orta diferansiye adenokarsinom olarak rapor edildi (Şekil 3). Klinik değerlendirmede tümör evre I olarak tanımlandı ve hastaya üç kür adjuvan kemoterapi uygulandi. Hasta altı ayda bir yapılan bilgisayarlı tomografi ve serum tümör markerleri düzeyinin ölçümü ile takibe alındı. Otuz altı aylık takipte yineleme görülmedi.

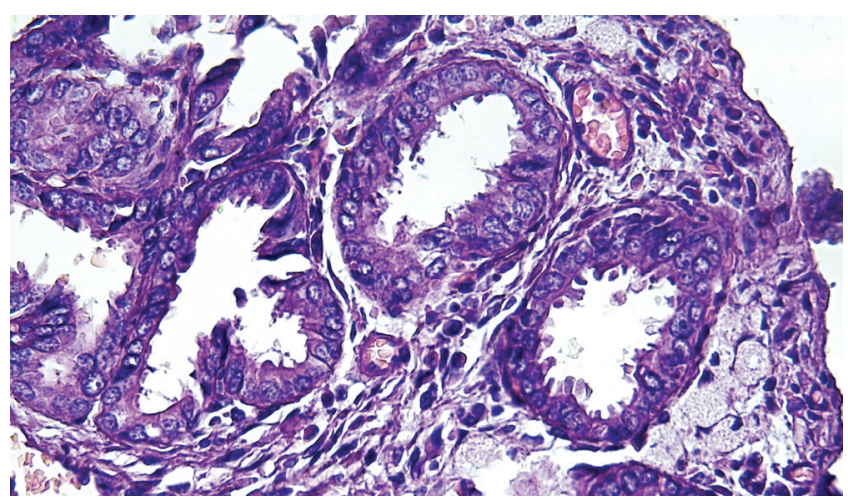

Şekil 1. Safra kesesi epitelinde çekirdeklerde pleomorfizm, kaba kromatin paterni ve nukleol belirginliği ile kendini gösteren ağır displazi (H\&E X 200)

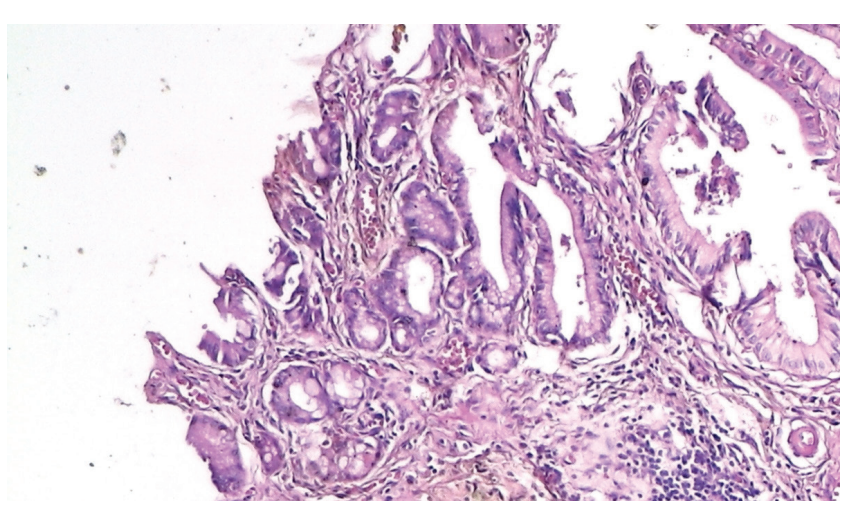

Şekil 2. Yüzey epitelinde intestinal metaplazi için karakteristik goblet hücreleri (H\&E X 200)

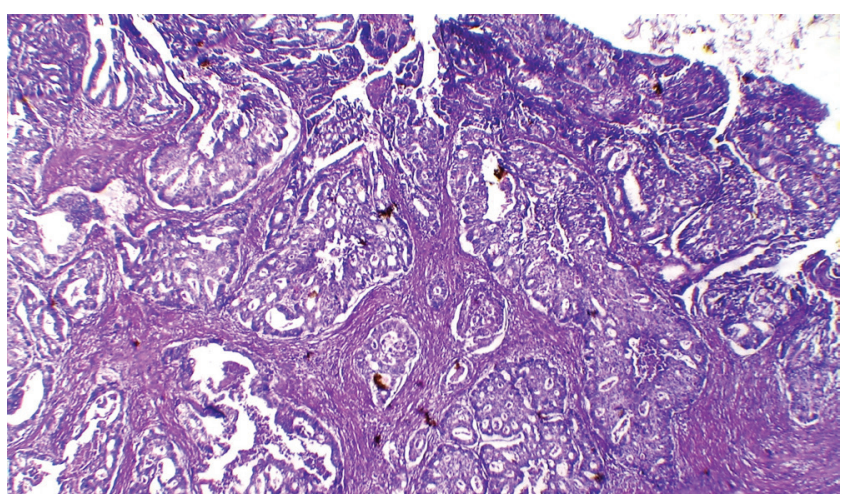

Şekil 3. Safra kesesi duvarında orta diferansiye adenokarsinom (H\&E X 200) 


\section{Tartışma}

Kolesistektomi, safra kesesi hastalıklarının tedavisi için genel cerrahi pratiğinde sık uygulanan bir yöntemdir. Teknolojinin hızlı gelişimi ile birlikte açık kolesistektomi yerini daha az invaziv olan laparoskopik kolesistektomiye bırakmaktadır. Ameliyat süresinin daha kısa olması, düşük komplikasyon ve mortalite riski, daha konforlu postoperatif dönem laparoskopik tekniğin başlıca avantajlarıdır [2]. Ama halen, hatta büyük merkezlerde bile uygulanan kolesistektomilerin bir kısmı için açık yönteme başvurulmaktadır. Genellikle klinisyenin bu konudaki kararını, safra kesesinde preoperatif olarak kanser kuşkusu, safra yolları ve kesenin doğumsal anomalileri, karaciğer sirozu, kanama bozuklukları, gebeliğin özellikle 3 . trimesteri, safra kesesi ve çevre doku arasında yapışıklıklar gibi faktörler etkilemektedir. Bu açıdan, laparoskopik veya açık kolesistektomi yardımı ile alınan safra keselerinin hastalıklarının dağılımı da farklılık gösterebilmektedir.

Kronik kolesistit, safra kesesinde en s1k rastlanan hastalıktır. Yapılan kolesistektomilerin büyük kısmını kronik kolesistitler oluşturmaktadır [3-5]. Bir çok çalışmada kronik kolesistitli olguların \% 90'dan fazlasında kolelitiazis görülmektedir. Hem kolelitiazis hem de kronik kolesistit insidansı büyük farkla kadınlarda daha yüksektir [6,7]. Çalışmamızda da en çok belirlenen tanı kronik kolesistit olmuştur ve kadın:erkek oranı 3:1 şeklinde idi.

Kolelitiazisin, kronik kolesistitin gelişiminde ne tür bir etkiye sahip olduğu tam olarak bilinmemektedir. Taşların çapı ve sayısı ile mukozal hasar arasında anlamlı bir uyum bulunmamaktadır [8]. Olguların yaklaşık 1/3'de safra kültürü pozitifdir. En sık rastlanan ajanlar E.coli ve enterokok olmakla birlikte Helicobacter, Giardia lamblia ve Salmonella typhi'ye de rastlanmaktadır $[9,10]$.

Mikroskopik özellikleri esas alınarak kronik kolesistitlerin bazı alt tipleri ayırt edilmektedir. Literatürde lenfoplazmasitik, AIDS ile ilişkili, folliküler, eozinofilik, granulomatöz, ksantogranulomatöz gibi alt tipler mevcuttur. Lenfoplazmasitik varyant genellikle akalkülöz kolesistit şeklinde gelişerek otoimmün hastalıklara eşlik etmektedir [11-13]. Lamina propriayı dolduran germinal merkeze sahip lenfoid folliküllerin görüldüğü kolesistitler ise folliküler kolesistit olarak bilinmektedir ve kolesistektomi spesimenlerinin \% 0,1'ni oluşturmaktadır [14]. AIDS ile ilişkili kolesistitlerin oluşumunda sitomegalovirüs, candida, mycobacterium ve microsporidia gibi immünsupresif hastalar için karakteristik olan etkenler önemli role sahiptir [15-17]. Safra kesesi mukozasında diğer inflamatuvar hücreler ile birlikte $\% 90$ 'dan fazla eozinofilik infiltrasyonun bulunduğu olgular ise eozinofilik kolesistit olarak rapor edilmektedir ve kolesistektomi materyallerinin \%20'ni oluşturmaktadır. Eozinofilik kolesistitin başlıca nedenleri hipereozinofilik sendrom, eosinofili-miyalji sendromu, parazitik enfeksiyonlar, bazı bitkisel ve diğer ilaçlardır [18,19]. Kronik kolesistitlerin mikroskopik özelliğe sahip bir diğer tipi ksantogranulomatöz kolesistittir.Makroskopik ve radyolojik olarak bazen malignite görüntüsü verebilir ve bu yüzden tanı sürecinde histopatoloji önem arz etmektedir [20]. Mikroskopik olarak safra kesesi duvarında karışık inflamatuvar hücre infiltrasyonunun yanı sıra çok sayıda köpüklü makrofaj gruplarının görülmesi karakteristik özelliğidir [6]. Bazen de safra kesesi duvarında kolesterol kristallerinin depolanmasına bağlı oluşan granulomatöz inflamasyon görülebilmektedir. Çalışmamızda kronik kolesistitli olguların sadece $\% 3,03$ 'de kronik inflamasyonun özel varyantlarına rastlanmıştır.

Kronik kolesistitlerden farklı olarak akut kolesistitlerin klinik ve patolojik tanımlaması farklıdır. Klinik olarak akut belirtiler ile kliniğe başvuran ve acil cerrahi uygulanan olguların bir çoğunda patolojik olarak akut yang1 bulgularına (örneğin nötrofil infiltrasyonuna) rastlanmamaktadır. Patolojik olarak akut kolesistit kavramı flegmanöz ve gangrenöz kolesistitler için kullanılmaktadır [6]. Genellikle kole(doko)litiazis ile birlikte görülmektedir fakat özellikle diyabet hastalarında sık rastlanan akalkulöz akut kolesistit olgularına da rastlanmaktadır [21,22]. Laparoskopik cerrahinin yeni yaygınlaşmaya başladığ 1 y1llarda akut kolesistitli olgular için laparoskopik kolesistektominin kontrendike olduğu fikri kabul görmüştü [23]. Fakat,sonradan yapılan araştırmalarda akut kolesistit olgularında da laparoskopik cerrahinin güvenle uygulanabileceği kanıtlandı. Yapılan bir kaç çalışmada ise akut kolesistitin laparoskopik kolesistektomiden açığa geçiş için sık rastlanan bir endikasyon olduğu vurgulanmıştır [24].

Kolesterolozis safra kesesi duvarındaki makrofajların sitoplazmasinda kolesterol esterleri ve trigliseridlerin toplanması sonucu oluşmaktadır. Makroskopik olarak mukoza yüzeyinde sarı çizgiler (çilek kese) veya 0,1-0,5 cm'lik polipoid lezyonlar şeklinde görülmektedir [25]. Polipoid lezyon şeklinde görülenleri kolesterol polibi olarak da bilinmektedir ve safra kesesinde en sik rastlanan polip tipidir. Safra kesesi mukozasında aynı zamanda çeşitli inflamatuvar, reaktif ve neoplastik poliplere de rastlamak mümkündür $[2-6,26]$. Çalışmamızda safra kesesi polibi belirlenen tüm olgularda kolesterol polibi saptanmıştır.

Özellikle kronik kolesistitli olguların bir kısmında mukozada metaplazi ve displazi gibi prekanseröz lezyonlar görülebilmektedir. En sık görülen metaplazi şekli antral, 
intestinal ve skuamoz metaplazidir [5,27]. Displazi belirlenen olgularda bu lezyonlar çoğunlukla düşük derecelidir. Bu lezyonlar tekbaşına olduğu gibi az rastlanan safra kesesi ve safra yolları adenomlarının komponenti olarak da karşımıza çıkabilmektedir. Çalışmamızda sadece dört olguda displazi, 46 olguda ise metaplazi izlendi.

Safra kesesinin malign tümörleri çok sık görülmemekle birlikte hepatobiliyer sistemdeki malign tümörlerin \%8095'nin lokalizasyonu safra kesesidir [28]. Burada en çok rastlanan malign tümör adenokarsinomdur. Daha az sıklıkla skuamoz hücreli karsinom, adenoskuamoz karsinom, küçük hücreli karsinom, indiferansiye karsinom ve diğer tümörler görülebilmektedir [26]. Klinik olarak safra kesesi malignitelerinin önemli bir k1smı asemptomatiktir ve histopatolojik incelemede insidental olarak bulunmaktadır. Serimizde sadece bir malignite vard 1 ve insidental olarak histopatolojik incelemede saptanmıştı.

Bazı çalışmalarda mikroskopik incelemeye alınan örnek sayısını arttırarak displazi ve metaplazi gibi prekanseröz lezyonların görülme sıklığında artış elde edilmiştir [29]. Çalışmaya alınan hastalarımızda her safra kesesinden en az üç örnek alınmıştır. Makroskopik olarak kuşkulu bulunan ve/veya kitlesel lezyonların bulunduğu, safra kesesi duvarının fibrotik ve kalın olduğu bazı olgularda örnek sayısı arttırılabilir. Örnek sayısının arttırılması, mevcut lezyonların mikroskopik incelemede daha kolay saptanabilmesi ve daha detaylı incelenmesi, bunun yanı sira makroskopik olarak görülemeyen lezyonların belirlenmesi açısından önem arz etmektedir. Aynı zamanda yeterli sayıda alınan örnek malign tümörlerin evrelemesinde hata payını en aza indirmeğe hizmet etmektedir.

Sonuç olarak laparoskopik kolesistektomi uygulanan olgulardan ibaret serimizde kronik kolesistit ve kolelitiazis önemli farkla en çok belirlenen tanılar olmuştur. Malignite sadece bir olguda $(\% 0,24)$ insidental olarak belirlenmiştir. Klinik olarak bulgu göstermeyen malignitelerin ve/veya prekanseröz lezyonların saptanabilmesi, aynı zamanda ksantogranulomatöz kolesistit gibi malignite kuşkusu oluşturan olguların ekarte edilmesi için kolesistektomi spesimenlerinin rutin olarak, dikkatli bir makroskopik inceleme yapılarak ve gerektiğinde alınan örnek sayısını arttırarak histopatolojik incelemeye tabi tutulması gerektiği kanisindayiz.

\section{Kaynaklar}

1. Lowsiriwat V, Vongjirad A, Lowsiriwat D. Value of routine histopathologic examination of three common surgical specimens: appendix, gallbladder, and hemorrhoid. World J
Surg 2009; 33:2189-93. doi: 10.1007/s00268-009-0164-6.

2. Kroh M, Chalikonda S, Chand B, Walsh M. Laparoscopic completion cholecystectomy and common bile duct exploration for retained gallbladder after single-incision cholecystectomy. JSLS 2013;17:143-7. doi: 10.4293/108680 812 X13517013317356.

3. Memon W, Khanzada TW, Samad A, Kumar B. Histopathology spectrum of gallbladder specimens after cholecystectomy. Pak J Med Sci 2011;27: 533-6.

4. Siddiqui FG, Memon AA, Abro AH, Sasoli NA, Ahmad L. Routine histopathology of gallbladder after elective cholecystectomy for gallstones: waste of resources or a justified act? BMC Surg 2013;13:26. doi: 10.1186/14712482-13-26.

5. Mazlum M, Dilek FH, Yener AN, Tokyol Ç, Aktepe F, Dilek ON. Profile of gallbladder diseases diagnosed at Afyon Kocatepe University: a retrospective study. Turk Patoloji Derg 2011;27:23-30.

6. Adsay NV. Gallbladder, extrahepatic biliary tree, and ampulla. In: Mills SE, Carter D, Greenson JK, Reuter VE, Stoler MH, editors. Sternberg's Diagnostic Surgical Pathology. Vol 2. 5th ed. Philadelphia, PA: Lippincott Williams \& Wilkins, 2010:1600-51.

7. Jagannath SB, Singh VK, Cruz-Correa M, Canto MI, Kalloo AN. A long-term cohort study of outcome after cholecystectomy for chronic acalculous cholecystitis. Am J Surg 2003;185:91-5.

8. Domeyer PJ, Sergentanis TN, Zagouri F, et al. Chronic cholecystitis in elderly patients. Correlation of the severity of inflammation with the number and size of the stones. In Vivo 2008;22:269-72.

9. Blaser MJ. Helicobacters and biliary tract disease. Gastroenterology 1998;114:840-5.

10. Leong RW, Sung JJ. Review article: Helicobacter species and hepatobiliary diseases. Aliment Pharmacol Ther 2002;16:1037-45.

11. Deshpande V, Mino-Kenudson M, Brugge W, Lauwers GY. Autoimmune pancreatitis: more than just a pancreatic disease? A contemporary review of its pathology. Arch Pathol Lab Med 2005;129:1148-54.

12. Abraham SC, Cruz-Correa M, Argani P, Furth EE, Hruban RH, Boitnott JK. Lymphoplasmacytic chronic cholecystitis and biliary tract disease in patients with lymphoplasmacytic sclerosing pancreatitis. Am J Surg Pathol 2003;27:441-51.

13. Abraham SC, Cruz-Correa M, Argani P, Furth EE, Hruban RH, Boitnott JK. Diffuse lymphoplasmacytic chronic cholecystitis is highly specific for extrahepatic biliary tract disease but does not distinguish between primary and secondary sclerosing cholangiopathy. Am J Surg Pathol 2003;27:1313-20.

14. Hatae Y, Kikuchi M. Lymph follicular cholecystitis. Acta Pathol Jpn1979;29:67-72.

15. French AL, Beaudet LM, Benator DA, Levy CS, Kass M, Orenstein JM. Cholecystectomy in patients with AIDS: clinicopathologic correlations in 107 cases. Clin Infect Dis 
$1995 ; 21: 852-8$.

16. Kavin H, Jonas RB, Chowdhury L, Kabins S. Acalculous cholecystitis and cytomegalovirus infection in the acquired immunodeficiency syndrome. Ann Intern Med 1986;104:534.

17. Nash JA, Cohen SA. Gallbladder and biliary tract disease in AIDS. Gastroenterol Clin North Am 1997;26:323-35.

18. Hepburn A, Coady A, Livingstone J, Pandit N. Eosinophilic cholecystitis as a possible late manifestation of the eosinophiliamyalgia syndrome. Clin Rheumatol 2000;19:470-2.

19. Choudhury M, Pujani M, Katiyar Y, Jyotsna PL, Rautela A. Idiopathic eosinophilic cholecystitis with cholelithiasis: a report of two cases. Turk Patoloji Derg 2014;30:142-4. doi: 10.5146/tjpath.2014.01235.

20. Ishii $T$, Hatano $E$, Yasuchika $K$, et al. $A$ case xanthogranulomatous cholecystitis suspected to be adenocarcinoma based on the intraoperative peritoneal washing cytology. Int J Surg Case Rep 2014;5:138-41. doi: 10.1016/j.ijscr.2014.01.011.

21. Knab LM, Boller AM, Mahvi DM. Cholecystitis. Surg Clin North Am 2014;94:455-70. doi: 10.1016/j.suc.2014.01.005.

22. Pal K. Laparoscopy in the management of emphysematous cholecystitis and secondary appendicitis in an 11-year-old child with insulin-dependent diabetes mellitus. Afr J Paediatr Surg 2011;8:211-4. doi: 10.4103/0189-6725.86065.

23. Ezberci F, Kale İT, Taşçı T, Kargı H, Ekerbiçer H, Kurtul A.
Akut kolesistit laparoskopik yaklașım için bir engel midir? Ulus Travma Acil Cerrahi Derg 2000;6:185-8.

24. Le VH, Smith DE, Johnson BL. Conversion of laparoscopic to open cholecystectomy in the current era of laparoscopic surgery. Am Surg 2012;78:1392-5.

25. Sandri L, Colecchia A, Larocca A, et al. Gallbladder cholesterol polyps and cholesterolosis. Minerva Gastroenterol Dietol 2003;49:217-24.

26. Albores-Saavedra J, Kloppel G, Adsay NV, et al. Carcinoma of the gallbladder and extrahepatic bile ducts In: Bosman FT, Carneiro F, Hruban RH, Theise ND, editors. WHO Classification of Tumors of the Digestive System. 4th ed. Lyon:IARC Press, 2010:266-73.

27. Seretis C, Lagoudianakis E, Gemenetzis G, Seretis F, Pappas A, Gourgiotis S. Metaplastic changes in chronic cholecystitis: implications for early diagnosis and surgical intervention to prevent the gallbladder metaplasia-dysplasia-carcinoma sequence. J Clin Med Res 2014;6:26-9. doi: 10.4021/ jocmr1689w.

28. Hundal R, Shaffer EA. Gallbladder cancer: epidemiology and outcome. Clin Epidemiol 2014;6:99-109.

29. Bolat F, Kayaselçuk F, Nursal TZ, Bal N, Tuncer İ. Kolesistektomilerde örnek sayısının artırılması ile histopatolojik bulguların korelasyonu. Turk Patoloji Derg 2007;23:137-42. 